\title{
PERAN KEPUASAN DI DALAM MEMEDIASI KUALITAS PRODUK DAN KUALITAS PELAYANAN TERHADAP LOYALITAS NASABAH BANK JATENG CABANG PURWODADI
}

\author{
Jarot Santosa $^{1^{*}}$, Denny Mahendra ${ }^{2}$, Aris Tri Haryanto ${ }^{3}$ \\ Sekolah Tinggi Ilmu Ekonomi Adi Unggul Bhirawa Surakarta \\ Email:*jrtsnts@gmail.com
}

\begin{abstract}
ABSTRAK
Tujuan penelitian adalah menganalisis dan memberikan bukti empiris signifikansi Pengaruh kualitas produk, kualitas pelayanan terhadap kepuasan nasabah Bank Jateng Cabang Purwodadi. Pengaruh kualitas produk, kualitas pelayanan, kepuasan terhadap loyalitas nasabah Bank Jateng Cabang Purwodadi. Populasi dalam penelitian ini adalah nasabah di Bank Jateng Cabang Purwodadi yang berkunjung pada bulan Desember 2019 sejumlah sekitar 800 nasabah. Sampel yang diambil dalam penelitian ini adalah sebesar 10\% dari populasi yaitu sebesar 80 nasabah, dengan teknik acidential sampling dengan cara acak. Hasil penelitian menunjukkan bahwa Kualitas produk berpengaruh positif dan signifikan terhadap kepuasan nasabah. Kualitas pelayanan berpengaruh negatif dan tidak signifikan terhadap kepuasan nasabah. Kualitas produk berpengaruh positif dan signifikan terhadap loyalitas Nasabah. Kualitas pelayanan berpengaruh positif dan signifikan. Kepuasan nasabah berpengaruh positif dan signifikan terhadap Loyalitas Nasabah. Hasil analisis jalur menunjukkan bahwa: Pengaruh langsung produk dan kualitas pelayanan terhadap loyalitas lebih besar dari pengaruh tidak langsung, sehingga untuk meningkatkan loyalitas lebih efektif melalui jalur langsung.
\end{abstract}

Keywords : kualitas produk, kualitas pelayanan, kepuasan nasabah, loyalitas nasabah.

\section{PENDAHULUAN}

Kualitas layanan yang berkaitan dengan kepuasan ditentukan oleh lima unsur yang biasa dikenal dengan istilah kualitas layanan "RATER" (responsiveness, assurance, tangible, empathy dan reliability). Konsep kualitas layanan RATER intinya adalah membentuk sikap dan perilaku dari pengembang pelayanan untuk memberikan bentuk pelayanan yang kuat dan mendasa. Adanya berbagai usaha perbankan yang berdiri membuat persaingan semakin kompetitif, dan pihak perbankan berlomba-lomba untuk memberikan tawaran yang menarik yang dapat menarik konsumen untuk dapat bertransaksi. Hal ini semata-mata tidak berhenti pada keinginan bertransaksi saja akan tetapi bagaimana membentuk nasabah yang loyal terhadap perbankan, sehingga tidak jarang setiap perbankan memberikan kemudahan pelayanan agar nasabah merasa puas dan loyal atas pelayanan yang diberikan. "Customers satisfaction is defined as the overall attitudes regarding good or service after its acquisition and uses". Oleh karena itu, perusahaan seperti perbankan harus dapat memenuhi kebutuhan dan keinginan nasabah atau sesuai dengan tingkat yang diinginkan oleh nasabah.

Lembaga keuangan bank adalah salah satu lembaga keuangan yang mempunyai peranan penting bagi nasabah, sehingga keberhasilan bank terletak pada kemampuannya menarik nasabah untuk menjadi nasabah yang loyal. Pemberian layanan prima merupakan kunci keunggulan bersaing bagi setiap perbankan, sehingga adanya pelayanan prima akan membentuk kepercayaan nasabah terhadap produk atau jasa yang ditawarkan. Atas dasar hal tersebut loyalitas menjadi hak mutlak bagi perbankan untuk meningkatkan kualitas produk dan kualitas pelayanan baik berupa barang maupun jasa.

Nurbiyati (2014) berpendapat bahwa di dalam konsep relationship marketing pemasar sangat menekankan pentingnya hubungan baik jangka panjang dengan nasabah dan infrastruktur pemasaran dan secara structural organisasional, kesadaran tersebut diwujudkan dalam bentuk-bentuk hubungan dan komitmen yang menyeluruh. Relationship marketing dapat dipandang sebagai koreksi yang 
cukup mendasar atas pemikiran dan praktek pemasaran yang telah ada sebelumnya terutama terhadap praktek pemasaran yang lebih menekankan azas transaksi (one time transaction marketing). Konsep ini dapat juga dianggap lebih maju dibandingkan dengan konsep marketing driven strategy. Jika konsep market bassed transaction menekankan pada bagaimana pemasar dapat menciptakan transaksi berikutnya.

Relationship marketing telah berkembang menjadi paradigma baru bagi strategi bisnis dan strategi pemasaran. Relationship marketing mampu memberdayakan kekuatan keinginan nasabah dengan tekanan teknologi informasi untuk memberikan kepuasan pada nasabah (Nurbiyati, 2014). Dewasa ini perhatian terhadap kepuasan pelanggan semakin diprioritaskan. Persaingan yang semakin tinggi dimana banyak perusahaan terlibat dalam pemenuhan kebutuhan keinginan pelanggan, menyebabkan pelanggan perusahaan harus menempatkan dan berorientasi kepada pelanggan sebagai tujuan utama.

Fenomena yang terjadi di lapangan terkait menurunnya loyalitas nasabah terhadap bank tidak menutup kemungkinan disebabkan oleh kualitas pelayanan yang buruk terhadap nasabah. Selain itu akibat kurangnya kualitas pelayanan kepada nasabah yang diberikan mengakibatkan banyak nasabah memindahkan dananya ke bank lain yang lebih baik dalam hal kualitas pelayanannya. Perusahaan yang telah berdiri akan memasarkan produk perbankan hingga dapat bersaing di kalangan perbankan lainnya. Persaingan kualitas produk yang semakin tinggi akan berdampak pada kepercayaan nasabah, maka itu dibutuhkannya pemasaran agar perusahan dapat berkembang dengan pesat. Kemampuan produk layanan yang baik akan berdampak pada pemakainya dan akan menguatkan atau bisa mendapatkan posisi terbaik di hati nasabah, sehingga layanan sangatlah penting bagi perbankan. Perbankan harus tetap menjaga kualitas dari perbankan agar pada pangsa pasar perbankan mempunyai citra yang baik di kalangan nasabah.

Kepuasan nasabah merupakan faktor yang sangat penting dan menentukan keberhasilan suatu bank karena nasabah adalah pengguna dari barang yang dihasilkannya. Jika nasabah merasa puas diharapkan akan dapat menciptakan loyalitas nasabah tersebut.

Hasil penelitian yang dilakukan oleh Henri (2015), Yuliani (2012), Wu (2012), Bontis dan Booker (2012), Krismanto (2012), Puspitasari, (2011) menunjukkan bahwa kepuasan berpengaruh signifikan terhadap loyalitas, sedangkan penelitian yang dilakukan oleh Sasongko (2013) menunjukkan kepuasan berpengaruh tidak signifikan terhadap loyalitas.

Atas dasar fenomena, landasan teori dan kesenjangan hasil penelitian terdahulu (research gap) serta diasumsikan mendekati kondisi yang sebenarnya, maka akan diuji pengaruh kepuasan terhadap loyalitas Bank Jateng Cabang Purwodadi Kantor Kas Jumantono. Customer loyalty atau loyalitas nasabah sebagai komitmen secara mendalam dibentuk untuk membeli kembali atau penggunaan kembali barang atau jasa secara konsisten pada masa mendatang, meskipun terdapat pengaruh situasional dan usaha pemasaran lain yang dapat berkompeten untuk menjadikan perilaku perpindahan.

Loyalitas nasabah sering kali dipengaruhi oleh kualitas pelayanan yang diberikan oleh perbankan, sehingga peran kualitas pelayanan mempengaruhi loyalitas nasabah. Kualitas pelayanan merupakan suatu bentuk penilaian, terhadap tingkat layanan yang diberikan oleh Bank Jateng Cabang Purwodadi Kantor Kas Jumantono.

Hasil penelitian yang dilakukan oleh Henri (2015), Yuliani (2012), Wu (2012), Bontis dan Booker (2012), Krismanto (2012), Puspitasari (2011) menunjukkan bahwa kualitas pelayanan 
berpengaruh signifikan terhadap loyalitas, sedangkan penelitian yang dilakukan oleh Saputro (2013) menunjukkan bahwa kualitas pelayanan berpengaruh tidak signifikan terhadap loyalitas.

Atas dasar fenomena, landasan teori dan kesenjangan hasi penelitian terdahulu (research gap) serta diasumsikan mendekati kondisi yang sebenarnya, maka akan diuji pengaruh kualitas pelayanan terhadap loyalitas nasabah Bank Jateng Cabang Purwodadi Kantor Kas Jumantono. Menurut Tjiptono (2012) kualitas didefinisikan sebagai suatu kondisi dinamis yang berhubungan dengan produk, jasa, manusia, proses, dan lingkungan yang memenuhi atau melebihi harapan. Kualitas adalah sebuah kata yang bagi penyedia jasa dapat berguna dengan baik dan dapat dikerjakan dengan baik memikiki mutu yang bernilai harganya. Pelayanan yang baik juga mendukung kualitas atau mutu dari perusahaan itu sendiri, sehingga baiknya pelayanan berdampak pada tinggi rendahnya tingkat kepuasan nasabah. Hasil penelitian yang dilakukan oleh Henri (2015), Yuliani (2012), Wu (2012), Bontis dan Booker (2012), Krismanto (2012), Puspitasari, (2011) menunjukkan bahwa kualitas produk berpengaruh signifikan terhadap loyalitas, sedangkan penelitian Susanti (2012) menunjukkan bahwa kualitas produk berpengaruh tidak signifikan terhadap loyalitas.

Dari pengamatan awal pada Bank Jateng Cabang Purwodadi ditemukan fenomena bisnis yaitu semakin tajamnya persaingan di bidang perbankan dan mempertinggi loyalitas nasabah Bank Jateng Cabang Purwodadi karena ada persaingan yang terjadi antar perbankan. Upaya peningkatan perbaikan perlu dilakukan pada Bank Jateng Cabang Purwodadi tentang kualitas produk harus terus dijaga, kualitas pelayanan selalu bersaing dengan perusahaan lain, lokasi yang selalu diunggulkan dan kepuasan nasabah yang selalu diutamakan.

Berangkat dari fenomena dan pemikiran-pemikiran di atas, maka akan dilakukan penelitian mengenai "Peran Kepuasan di dalam memediasi Kualitas Produk dan Kualitas Pelayanan Terhadap Loyalitas Nasabah Bank Jateng Cabang Purwodadi”.

\section{METODE PENELITIAN}

Penelitian ini dilakukan dengan mengambil lokasi penelitian pada Bank Jateng Cabang Purwodadi. Dalam penelitian ini yang menjadi objek penelitian ini adalah nasabah pada Bank Jateng Cabang Purwodadi. Populasi dalam penelitian ini adalah nasabah di Bank Jateng Cabang Purwodadi yang berkunjung pada bulan Desember 2019 sejumlah sekitar 800 nasabah. Sampel yang diambil dalam penelitian ini adalah sebesar $10 \%$ dari populasi yaitu sebesar 80 nasabah, dengan teknik acidential sampling dengan cara acak.

\section{ANALISIS HASIL DAN PEMBAHASAN}

\section{Analisis Jalur (Path Analysis)}

\section{Analisis Jalur Persamaan 1}

Analisis jalur persamaan regresi pertama adalah sebagai berikut:

$\mathrm{Y}_{1}=0,382 \mathrm{X}_{1}-0,059 \mathrm{X}_{2}+\epsilon_{1}$

Dari hasil persamaan regresi di atas, maka dapat dijelaskan sebagai berikut:

1) $\beta_{1}=$ Nilai koefisien regresi produk sebesar 0,382 , hal ini menunjukkan bahwa produk berpengaruh positif terhadap kepuasan nasabah di Bank Jateng Cabang Purwodadi, ini berarti bahwa apabila produk ditingkatkan, maka kepuasan nasabah juga akan meningkat.

2) $\quad \beta_{2}=$ Nilai koefisien regresi kualitas pelayanan sebesar $-0,059$, hal ini menunjukkan bahwa kualitas pelayanan berpengaruh negatif terhadap kepuasan nasabah di Bank Jateng Cabang 
Purwodadi, hal ini berarti apabila kualitas pelayanan nasabah ditingkatkan, maka kepuasan nasabah kerja nasabah di Bank Jateng Cabang Purwodadi akan menurun.

\section{Hasil Analisis Jalur Persamaan 2}

Analisis jalur persamaan regresi kedua adalah sebagai berikut:

$\mathrm{Y}_{2}=0,551 \mathrm{X}_{1}+0,211 \mathrm{X}_{2}+0,278 \mathrm{X}_{3}+\epsilon_{2}$

Dari hasil persamaan regresi di atas, maka dapat dijelaskan sebagai berikut:

1) $\beta_{1}=$ Nilai koefisien regresi kualitas produk sebesar 0,551 , hal ini menunjukkan bahwa produk berpengaruh positif terhadap loyalitas nasabah di Bank Jateng Cabang Purwodadi, apabila produk ditingkatan maka loyalitas nasabah di Bank Jateng Cabang Purwodadi akan meningkat.

2) $\beta_{2}=$ Nilai koefisien regresi kualitas pelayanan sebesar 0,211 , hal ini menunjukkan bahwa kualitas pelayanan berpengaruh positif terhadap loyalitas nasabah di Bank Jateng Cabang Purwodadi, hal ini berarti apabila kualitas pelayanan ditingkatkan maka loyalitas nasabah di Bank Jateng Cabang Purwodadi akan meningkat.

3) $\beta_{3}=$ koefisien regresi kepuasan nasabah sebesar 0,278 , hal ini menunjukkan bahwa kepuasan nasabah berpengaruh positif terhadap loyalitas nasabah di Bank Jateng Cabang Purwodadi, hal ini berarti apabila kepuasan nasabah ditingkatkan maka loyalitas nasabah di Bank Jateng Cabang Purwodadi akan meningkat.

\section{Uji Parsial (t)}

\section{Uji t Persamaan Pertama}

Tabel I

Hasil Uji t Persamaan 1

\begin{tabular}{|l|c|c|c|}
\hline \multicolumn{1}{|c|}{ Variabel } & $\mathrm{t}$ & $\mathrm{sig}$ & Hasil \\
\hline Kualitas Produk & 3,494 & 0,001 & Terbukti \\
\hline Kualitas Pelayanan & $-0,536$ & 0,594 & Tidak Terbukti \\
\hline
\end{tabular}

Hasil uji t pada persamaan pertama dapat disimpulkan bahwa:

1) Pengaruh Kualitas Produk Terhadap Kepuasan nasabah

Kualitas Produk berpengaruh signifikan terhadap kepuasan nasabah di Bank Jateng Cabang Purwodadi, hal ini dapat dilihat dari nilai signifikansi yaitu $0,001<0,05$. Berdasarkan pengujian di atas dapat disimpulkan bahwa Hipotesis 1 terbukti.

2) Pengaruh Kualitas pelayanan Terhadap Kepuasan nasabah

Kualitas pelayanan berpengaruh tidak signifikan terhadap Kepuasan nasabah di Bank Jateng Cabang Purwodadi, hal ini dapat dilihat dari nilai signifikansi yaitu 0,594 >0,05. Berdasarkan pengujian di atas dapat disimpulkan bahwa Hipotesis 2 tidak terbukti.

\section{Uji t Persamaan Kedua}

Tabel II

Hasil Uji t Persamaan 2

\begin{tabular}{|l|c|c|c|}
\hline \multicolumn{1}{|c|}{ Variabel } & $\mathrm{t}$ & $\mathrm{sig}$ & Hasil \\
\hline Produk & 6,413 & 0,000 & Diterima \\
\hline Kualitas Pelayanan & 2,649 & 0,010 & Diterima \\
\hline Kepuasan & 3,245 & 0,002 & Diterima \\
\hline
\end{tabular}


Dari Uji t pada persamaan kedua dapat disimpulkan bahwa:

1) Pengaruh Kualitas Produk Terhadap Loyalitas Nasabah

Kualitas Produk berpengaruh signifikan terhadap loyalitas nasabah di Bank Jateng Cabang Purwodadi, hal ini dapat dilihat dari nilai signifikansi yaitu $0,000<0,05$. Berdasarkan pengujian di atas dapat disimpulkan bahwa Hipotesis 3 terbukti.

2) Pengaruh Kualitas pelayanan Terhadap Loyalitas Nasabah

Kualitas pelayanan berpengaruh signifikan terhadap loyalitas nasabah di Bank Jateng Cabang Purwodadi, hal ini dapat dilihat dari nilai signifikansi yaitu $0,010<0,05$. Berdasarkan pengujian di atas dapat disimpulkan bahwa Hipotesis 4 terbukti.

3) Pengaruh Kepuasan nasabah Terhadap Loyalitas Nasabah

Kepuasan nasabah berpengaruh signifikan terhadap loyalitas nasabah di Bank Jateng Cabang Purwodadi, hal ini dapat dilihat dari nilai signifikansi yaitu $0,002<0,05$. Berdasarkan pengujian di atas dapat disimpulkan bahwa Hipotesis 5 terbukti.

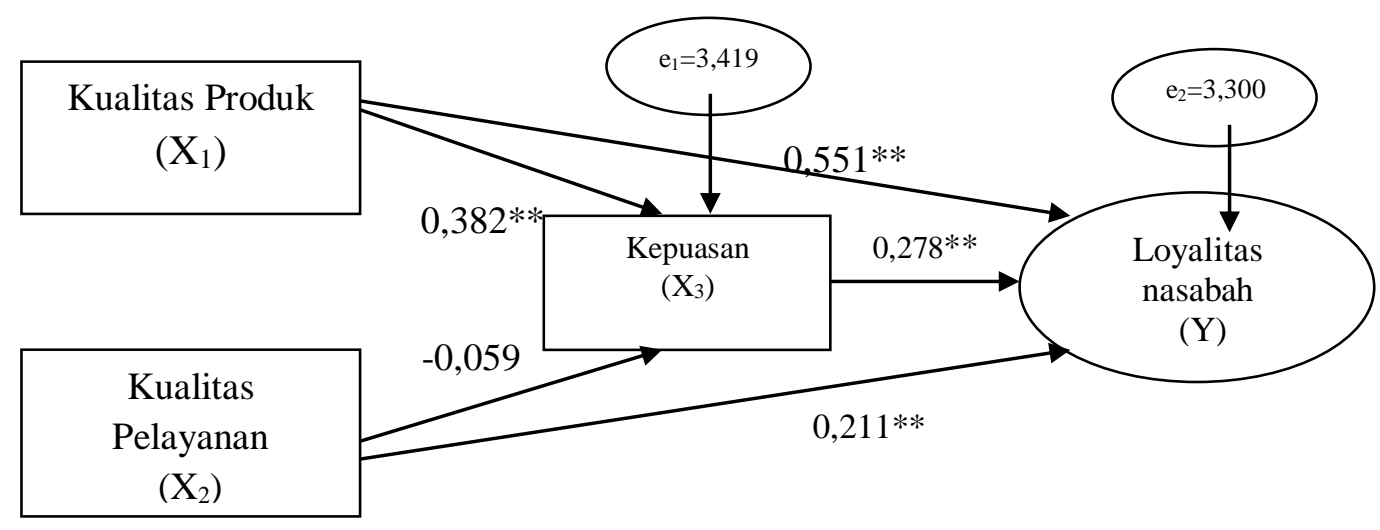

Gambar IV.1 Hasil Pengaruh Langsung dan Tidak Langsung

\section{PEMBAHASAN}

1. Pengaruh kualitas produk terhadap loyalitas

Analisis jalur menunjukkan bahwa penggunaan variabel intervening kepuasan nasabah dalam rangka peningkatan loyalitas, untuk variabel kualitas produk adalah tidak efektif, karena pengaruh langsung menghasilkan pengaruh yang yang lebih besar. Hal ini berarti, untuk meningkatkan loyalitas nasabah di Bank Jateng Cabang Purwodadi sebaiknya memperhatikan faktor-faktor dalam meningkatkan kualitas produk di Bank Jateng Cabang Purwodadi. Hasil penelitian ini mendukung penelitian Saputro, (2013), Susanti (2012) dan Puspitasari, (2011).

Upaya untuk meningkatkan kualitas produk dapat dilakukan seperti:

a. Meningkatkan keamanaan transaksi nasabah di Bank Jateng Cabang Purwodadi.

b. Meningkatkan variasi kredit yang menarik.

c. Meningkatkan suku bunga yang menarik.

2. Pengaruh kualitas pelayanan terhadap loyalitas melalui kepuasan nasabah

Penggunaan variabel intervening kepuasan nasabah dalam rangka peningkatan loyalitas, untuk variabel kualitas pelayanan adalah tidak efektif, karena pengaruh tidak langsung menghasilkan pengaruh yang lebih kecil dari pada pengaruh langsung. Hal ini berarti, untuk meningkatkan loyalitas nasabah di Bank Jateng Cabang Purwodadi sebaiknya memperhatikan 
variabel kualitas pelayanan dan memperhatikan faktor-faktor yang menimbulkan tingginya kualitas pelayanan di Bank Jateng Cabang Purwodadi. Hasil penelitian ini mendukung penelitian Henri, (2015), Wu (2012), Krismanto (2012), Puspitasari, (2011).

Upaya untuk meningkatkan kualitas pelayanan adalah dengan cara:

a. Meningkatkan empati (Emphaty) atau perhatian kepada semua nasabah.

b. Meningkatkan keandalan atau ketelitian dalam pelayanan (Reliability).

c. Meningkatkan daya tanggap atas keperluan nasabah (Responsive).

\section{KESIMPULAN}

1. Kualitas produk berpengaruh positif dan signifikan terhadap kepuasan nasabah di Bank Jateng Cabang Purwodadi.

2. Kualitas pelayanan berpengaruh negatif dan tidak signifikan terhadap kepuasan nasabah di Bank Jateng Cabang Purwodadi.

3. Kualitas produk berpengaruh positif dan signifikan terhadap loyalitas Nasabah di Bank Jateng Cabang Purwodadi.

4. Kualitas pelayanan berpengaruh positif dan signifikan terhadap loyalitas nasabah di Bank Jateng Cabang Purwodadi.

5. Kepuasan nasabah berpengaruh positif dan signifikan terhadap Loyalitas Nasabah di Bank Jateng Cabang Purwodadi.

6. Hasil uji F menunjukkan secara bersama-sama bahwa kualitas produk, kualitas pelayanan dan kepuasan berpengaruh signifikan terhadap loyalitas nasabah di Bank Jateng Cabang Purwodadi.

7. Hasil nilai $\mathrm{R}^{2}$ total sebesar 0,619 dapat diartikan variasi loyalitas nasabah di Bank Jateng Cabang Purwodadi dijelaskan oleh variabel produk, kualitas pelayanan, dan kepuasan nasabah sebagai variabel intervening sebesar $61,9 \%$ dan sisanya 38,1\% dijelaskan variabel lain diluar model penelitian yaitu iklim organisasi, pengawasan, dan sebagainya.

8. Hasil analisis jalur menunjukkan bahwa: Pengaruh langsung produk dan kualitas pelayanan terhadap loyalitas lebih besar dari pengaruh tidak langsung, sehingga untuk meningkatkan loyalitas lebih efektif melalui jalur langsung.

\section{SARAN}

1. Kualitas Produk merupakan variabel yang paling dominan mempengaruhi loyalitas nasabah di Bank Jateng Cabang Purwodadi. Bank Jateng Cabang Purwodadi untuk lebih meningkatkan kualitas produk seperti :

a. Meningkatkan keamanaan transaksi nasabah di Bank Jateng Cabang Purwodadi, misalnya adanya keamanan data nasabah yang tidak di sebar luaskan.

b. Meningkatkan variasi kredit yang menarik, misalnya adanya kredit bagi petani, kredit pedagang dengan prosedur yang mudah.

c. Meningkatkan suku bunga yang menarik, misalnya adanya suku bunga tambahan bagi yang menabung dengan jumlah yang besar.

2. Kualitas pelayanan berpengaruh signifikan terhadap loyalitas nasabah di Bank Jateng Cabang Purwodadi. Bank Jateng Cabang Purwodadi untuk lebih meningkatkan kualitas pelayanan seperti :

a. Meningkatkan empati (Emphaty) atau perhatian kepada semua nasabah, misalnya memberikan pelayanan yang sama terhadap semua nasabah. 
b. Meningkatkan keandalan atau ketelitian dalam pelayanan (Reliability), misalnya pegawai mampu memberikan solusi bagi masalah yang disampaikan nasabah.

c. Meningkatkan daya tanggap atas keperluan nasabah (Responsive), misalnya pegawai merespon dengan cepat keluhan nasabah.

\section{DAFTAR PUSTAKA}

Agnes Niken Puspitasari. 2011. Analisis Pengaruh Kualitas Produk Dan Kualitas Pelayanan Terhadap Kepuasan Pelanggan Untuk Mendorong Minat Beli Ulang (Studi pada Pengguna Nokia di Semarang), Jurnal Bisnis Dan Manajemen Vol.2 No.4 Fakultas Ekonomi Universitas Diponegoro Semarang

Anderson, E. dan B. Weitz. 2013. "The Use of Pledges to Build and Sustain Commitment in Distribution Channel”, Journal of Marketing research 29 (1), p.18-34.

Bolton, Ruth N dan james H. Drew. 2011. “ A Multi Stage Model of Customers Assessment of Service Quality and Value", Journal of Consumer Research, Januari, 1-9.

Brown, Stephen W. 2011. “A Multi Stage Model of Customers Assesment of Service Quality and Value”, Journal of Marketing, April, pp. 92-98

Cronin J.Joseph Jr dan Steven A. Taylor. 2012. “ Measuring Service Quality : A reexamination and extension", Journal of Marketing Vol. 56 (July) p.55-68

Dharmmesta, Basu Swastha dan Licen Indahwati Darsono. 2009. "Kontribusi involvement dan trust in a brand dalam membangun loyalitas pelanggan" Jurnal Ekonomi dan Bisnis Indonesia, Vol. 20, No. 3 .

Fornell, Claes; Johnson, Michael D ; Anderson, Eugene W ; Cha, Jaesun; Bryant, Barbara Everitt. 2012. "The American Customer Satisfaction Index : Nature, Purpose, and Findings". Journal of Marketing, 60 (10). (7 - 18).

Gaspersz, Vincent. 2012. Three-in-one ISO 9001, ISO 14001, OHSAS 18001 Sistem Manajemen Kualitas, K3, Lingkungan (SMK4L) dan Peningkatan Terus-Menerus Contoh Aplikasi pada Bisnis dan Industri. Bogor: Vinchristo Publication

Herbig, Paul, John Milewicz and Jim Golden. 2013. "A Model of Reputation Building and Destruction "Journal of Business Research. Vol.31, June 1994, No. 1 ; p.23-31.

Istijanto. 2011, Riset Sumber Daya Manusia, Jakarta:PT. Gramedia Pustaka Utama

Juran, J.M. 2011. Quality Control Handbook, New York: Mc. Graw-Hill.

Kotler, Philip and Gary Armstrong. 2011. Prinsip-prinsip Pemasaran. Jakarta: Erlangga. 
Laudon, Kenneth C, Laudon Jane P. 2013. Sistem Informasi Manajemen (Management Information Systems, Managing the Digital Firm). Terjemahan Philippus Erwin. Edisi 8. Penerbit Andi. Yogyakarta.

Liu, Tsung-Chi and Li Wei Wu. 2012. "Customer retention and cross-buying in the perusahaaning industry: An Integration of service attributes, satisfaction and trust" Journal of Financial Service Marketing, Vol.12 No.2 p.132-145.

Lupiyoadi, Rambat. 2011. Manajemen Pemasaran Jasa. Jakarta: Salemba empat.

Mandela. 2012. "Study Mengenai Loyalitas Konsumen Pada Rumah Makan Start Stick (Studi khusus di Jawa Tengah)", Jurnal Sains Pemasaran Indonesia, Vol III, No.3, Desember 2007. (289308)

Marius. 2009. Consumer Behavion and Price, $5^{\text {th }}$ edition, McGraw Hill, New York, NY

Moenir. 2014. Manajemen Pelayanan Umum di Indonesia, Bumi Aksara,Jakarta.

Musanto. 2008. "Faktor-Faktor Kepuasan Pelanggan dan Loyalitas Pelanggan. Studi Kasus pada CV. Sarana Media Advertising Surabaya”. Jurnal Manajemen \& Kewirausahaan, Vol. 6, No. 2, September 2004, hal. $123-136$.

Nurbiyati, Titik. 2008. "Relationship marketing sebagai suatu strategi untuk meningkatkan keuntungan jangka panjang. Kajian Bisnis, No.14, Mei - September 2008, hal. 131-139

Oliver, Richard L. 2013. " Satisfaction : A Behavioral Perspective on the Customer", McGraw-Hill, New York, NY.

Parasuraman, A.,A.Zeithmal, V.,\& L.Berry, L. 2010” A conceptual Model of Service Quality and Its Implications for Future Research", Journal of Marketing, Vol.49 (fall).

Prichard, mark P. 2010, “Analyzing the Commitment-Loyalty Link in Service Contexts", Journal of the Academy of Marketing Science 27 (3), p.333-348

Rangkuti, Freddy. 2012. Measuring customer satisfaction : Teknik mengukur dan strategi meningkatkan kualitas pelanggan, Edisi keempat, cetakan kesatu, Jakarta: gramedia pustaka utama.

Riduwan. 2010, Skala pengukuran Variabel-Variabel Penelitian, Cetakan Ketiga, Alfabeta, Bandung.

Ropinov Saputro, 2013. Analisis Pengaruh Kualitas Produk, Kualitas Pelayanan, Dan Kepercayaan Pelanggan Terhadap Loyalitas Pelanggan (Studi Pada Pt. Nusantara Sakti Demak). Jurnal Bisnis Dan Manajemen Vol.2 No.4 Fakultas Ekonomi Universitas Diponegoro Semarang 
Selnes, Fred. 2013. "An Examination of the effect of Product Performance on Brand Reputation, Satisfaction and Loyalty", European Journal of Marketing, 27 (9). (19-35).

Singgih Priatmaji Sasongko. 2013. Analisis Pengaruh Kualitas Pelayanan, Kualitas pelayanan Kompetitif, Kelengkapan Barang Dan Lokasi Terhadap Loyalitas nasabah Di Swalayan Alfa Omega Baturetno, Wonogiri. Jurnal Manajemen dan Bisnis Vol. 2 No. 4 ISSN:109820436

Solomon, Michael. 2011. Consumer Behavion, $3^{\text {th }}$ edition, McGraw Hill.

Solvang, B.K. 2012. Satisfaction, Loyalty, and Repurchase. Journal of Consumer Satisfaction Dissatisfaction and Comlplaining Behavior, Vol. 20. no.7. halaman 152-160.

Tina Susanti. 2012. Analisis Pengaruh Kualitas Produk, Kualitas pelayanan, Lokasi dan Kualitas pelayanan Terhadap Loyalitas konsuemn (Studi Pada PD. BPR Bank Daerah Karanganyar). Jurnal Riset Vol. 3 No. 2 UMS Surakarta

Zeithaml, V. 2013. Consumer Perceptions of Price, "Quality, and Value : Means End Model and Synthesis of Evidence", Journal of Marketing, Vol 52, July, p.2-22

Zeithaml, Valerie; Berry, Leonard L, dan Parasuraman, A. 2012. "Sevqual: Multiple Item Scale for Measuring Consumer Perceptions of Service Quality", Journal of Retailing, Vol 64 No.1 Spring. 